\title{
Determination and Analysis of Land Deformation in Nairobi City County Based ALOS/Palsar and Sentinel-1 InSAR Processing
}

PIUS KIRUI ( $\sim$ p.kirui@tu-bs.de )

Technische Universitat Braunschweig https://orcid.org/0000-0002-7449-6147

\section{Samson Oiro}

Water Resources Authority,Kenya

\section{Hunja Waithaka}

JKUAT: Jomo Kenyatta University of Agriculture and Technology

\section{Patroba Odera}

University of Cape Town

\section{Björn Riedel}

TU Braunschweig: Technische Universitat Braunschweig

\section{Markus Gerke}

TU Braunschweig: Technische Universitat Braunschweig

\section{Research Article}

Keywords: Nairobi land subsidence, Nairobi Groundwater, InSAR, Depletion of Nairobi aquifer

Posted Date: July 16th, 2021

DOl: https://doi.org/10.21203/rs.3.rs-683067/v1

License: (9) (i) This work is licensed under a Creative Commons Attribution 4.0 International License. Read Full License 


\title{
Determination and analysis of land deformation in Nairobi City County based ALOS/Palsar and Sentinel-1 InSAR Processing
}

\author{
Pius kirui ${ }^{1,3}$. Samson Oiro ${ }^{2}$. Hunja waithaka ${ }^{3}$. \\ Patroba odera $^{4}$. Björn Riedel ${ }^{1}$. Markus Gerke ${ }^{1}$ \\ 7 the date of receipt and acceptance should be inserted later
}

6

\begin{abstract}
Nairobi city is one of the fastest-growing cities in Africa. The rapid development has put pressure on the existing resources such as water resulting in overexploitation of groundwater. Nairobi had been reported to be susceptible to environmental hazards such as subsidence associated with the overexploitation of groundwater due to depletion of its aquifer. However, the subsidence has not been empirically quantified because Kenya lacks a functioning deformation monitoring framework. Through the use of InSAR, land subsidence in Nairobi was spatially quantified for the first time that confirms fears of subsidence as suggested by previous hydrogeological studies. We observed an increase in the spatial extends and the rates of subsidence, the highest rate of subsidence being approx. $62 \mathrm{~mm} / \mathrm{yr}$ located in the largest deforming area West of Nairobi. The deformation can majorly be linked to overexploitation of groundwater as it matches with regions with the highest rate of decline of groundwater levels. However, there exist also subsidence linked to rapid development. Given the significance of Nairobi to the Kenyan economy, the ripple effects of subsidence could be devastating and measures need to be taken to mitigate them. The deformation map provides an important tool for planning mitigation measures to prevent further deformation such as regulating the drilling of boreholes, planning of construction of buildings and transport networks, and locations for the observation wells for monitoring groundwater levels. It also reinforces the need for updating the geodetic network that has been rendered unreliable due to land subsidence.
\end{abstract}

Keywords Nairobi land subsidence · Nairobi Groundwater · InSAR · Depletion of Nairobi aquifer

1. Institute of Geodesy and Photogrammetry Bienroder weg 81, 38126 Braunschweig ,Germany Tel.: +49 (0531) 391-94585

E-mail: p.kirui@tu-braunschweig.de

2. Water Resources Authority, Kenya

3. Jomo Kenyatta University Of Agriculture and Technology

4. University of Cape Town 


\section{Introduction}

Nairobi City, the capital city of Kenya is one of the fastest-growing cities in Africa (Ren et al., 2020). The current population of Nairobi city stands at 4.3 million as per the 2019 census (KNBS, 2019) which represents a growth of approximately $250 \%$ during the last three decades. The city serves as a host to various land use such as residential, industrial, transport, and commercial. The rapid population growth in the recent past has put pressure on the existing resources resulting in environmental problems such as pollution, flooding, and shortage of amenities such as housing and water. This is exemplified more in the increased demand for housing which has led to rapid urbanization Otiso and Owusu (2008), the development of high-rise buildings, shopping malls, and other infrastructural projects. Similarly, an exponential increase in the waste with no alternative sites for water disposal has put pressure on the existing landfill, Dandora landfill, with tones of waste being disposed of daily(Hudson Hill, 2020; Haregu et al., 2017). Aside from the obvious environmental hazards, the addition of 5000 tonnes of waste daily is a recipe for land subsidence to the adjacent properties mechanical and biochemical processes at the landfill is a recipe for land subsidence for the adjacent properties (Gasperini et al., 2014; Baek et al., 2019). Additionally, unplanned development in fragile environmental locations such as flood plains characterized by high population density could also induce subsidence (Rateb and Abotalib, 2020). The interplay of these factors together with the depletion of the aquifer could act as a catalyst to subsidence. Land subsidence has been associated with over-exploitation of groundwater but urbanization due to the rapid development of buildings can also contribute to land subsidence due to the consolidation process (Chen et al., 2015). The land subsidence due to the construction of new buildings has been reported for example in Ezquerro et al. (2020); Pratesi et al. (2016); Xu et al. (2012); Yang et al. (2018). Similarly, Nairobi city has witnessed rapid construction of high rise buildings even in regions that were not zoned for such buildings to meet the increasing housing demand (Makunda, 2018) which can lead to subsidence. The water exploitation induced subsidence is due to the increased distribution of effective stress in the strata and the compression of the aquifers (Guo et al., 2015). Land subsidence due to overexploitation of groundwater has been witnessed in other cities such as Mexico (Chaussard et al., 2014), China (Chen et al., 2003) Italy (Ezquerro et al., 2020), Nepal (Bhattarai et al., 2017), Taiwan (Hung et al., 2012), Indonesia (Abidin et al., 2011) and Brazil (de Luna et al., 2017). Nairobi's daily demand for water is 790,000 $\mathrm{m} 3$ against the supply of 525,000 m3 by Nairobi water Sewerage Company, the authority in charge of water supply in Nairobi. Due to unreliable piped water supply, the residential houses and other establishments depend on groundwater to ensure a consistent supply of water. The shortage in water supply has increased the overexploitation of the aquifer to meet the demand for residential, commercial and industrial activities (Chakava et al., 2014; Mumma et al., 2011). The rate of groundwater extraction has increased in proportional to the population growth leading to a depletion of the aquifer (Oiro et al., 2020). The depletion of the aquifer is characterized by the decrease water table, which has been reported to decrease at the rate of $3-7 \mathrm{~m}$ per year within Nairobi city. The decrease in the water table may consequently lead to land subsidence. For Nairobi, previous hydrogeological studies have acknowledged the possibility of subsidence associated with groundwater exploration. For instance, Foster and Tuinhof (2005),Nairobi City Council (2007) and Onyancha et al. (2012) reported on the fear of subsidence in Nairobi due to groundwater overexploitation. A similar observation was noted by Onyancha et al. (2011) who opined on the possibility of land subsidence in Nairobi due to overexploitation and its geology which was once a swamp. The first attempt to model the possible subsidence in Nairobi was by Mathu et al. 
(2014), who estimated a maximum of $5.9 \mathrm{~m}$ subsidence over the last $80 \mathrm{yrs}$, they noted that no subsidence had ever been reported in Nairobi associated with groundwater abstraction due to lack of deformation monitoring framework. Their estimates were based on the modelling of hydrogeological and piezometric data. Their estimates were cumulative and not spatially represented as is restricted to the location of observation wells with temporal data. Direct estimates of the rate of land subsidence that are spatially representative and have not been reported or quantified. Geodetic methods have been widely used to quantify the magnitude and spatial pattern of subsidence. These methods include leveling (Chrzanowski et al., 1989; Tosi et al., 2007), use of GNSS (Argyrakis et al., 2020; Ustun et al., 2010), and InSAR (Chaussard et al., 2014; Hirose et al., 2001). Levelling and GNSS show point deformation while InSAR has the capability of showing the areal subsidence. In Kenya, geodetic network maintenance and observation is the responsibility of the national mapping agency, the Survey of Kenya (SOK). Unfortunately, a modern and up to date geodetic network for mapping and other applications such as geophysical studies is lacking. The leveling geodetic network has not been updated or densified over the years, meaning that historical data needed for deformation monitoring are not available. Similarly, Kenya did not have a reliable GNSS network except for some three stations owned by International GNSS Service (IGS). Lately, however, there have been efforts by the private sector such as Measurement Systems Limited to establish their private geodetic network and deformation monitoring network such as Uganda-Kenya Eastern Branch GNSS Network (Stamps et al., 2019). However, the network is not large and dense enough to cover most of Nairobi City County, the study area,hence its applicability in deformation monitoring is still limited. The lack of accurate and sufficient geodetic data perhaps explains the lack of previous studies in deformation within the study area. Moreover, although InSAR has been used in other regions for monitoring subsidence, its application within Nairobi has not been reported. The use of InSAR as a geodetic tool for monitoring land subsidence due to groundwater extraction is well documented Guo et al. (2015); Neelmeijer et al. (2018). InSAR is based on observant of phase change; however, the conventional differential InSAR was faced with challenges of extracting deformation signal from other superimposed sources such as decorrelation and tropospheric modelling. Multitemporal InSAR Berardino et al. (2002); Ferretti et al. (2000) was later introduced to address these challenges. The resulting velocity measurement is the line of sight (LOS); through the use of data acquired in descending and ascending orbits, the vertical and east-west components can be derived Eriksen et al. (2017); Hu et al. (2014). The aim of this study, therefore, was to determine the deformation within Nairobi City County through the use of InSAR, taking advantage of the large data sets of Sentinel 1 data. The nature of deformation was determined by decomposing the LOS velocity estimates into vertical and East-west movement and finally assigning the deformation to its causative agent.

\section{Materials and Methods}

\subsection{Study area}

The study is being undertaken in Nairobi City County, the capital city of Kenya. The geographical extends of Nairobi, the elevation the processing extends limited to the footprint of the ascending orbit, the geology and the land cover of Nairobi is shown in Fig. 1. The geological structures of Nairobi are mainly underlain by pyroclastic volcanic rocks interposed with sediments that were deposited in a series of lakes that extended from Doinyo Sabuk to Kajiado (Matheson, 1966; Oiro et al., 2020; Onyancha et al., 2011). The specific geological 
formations are Nairobi phonolite, Kerichwa turfs, Nairobi trachytes, and Limuru trachyte, while other formations include Kabete trachytes and Mbagathati trachyte.

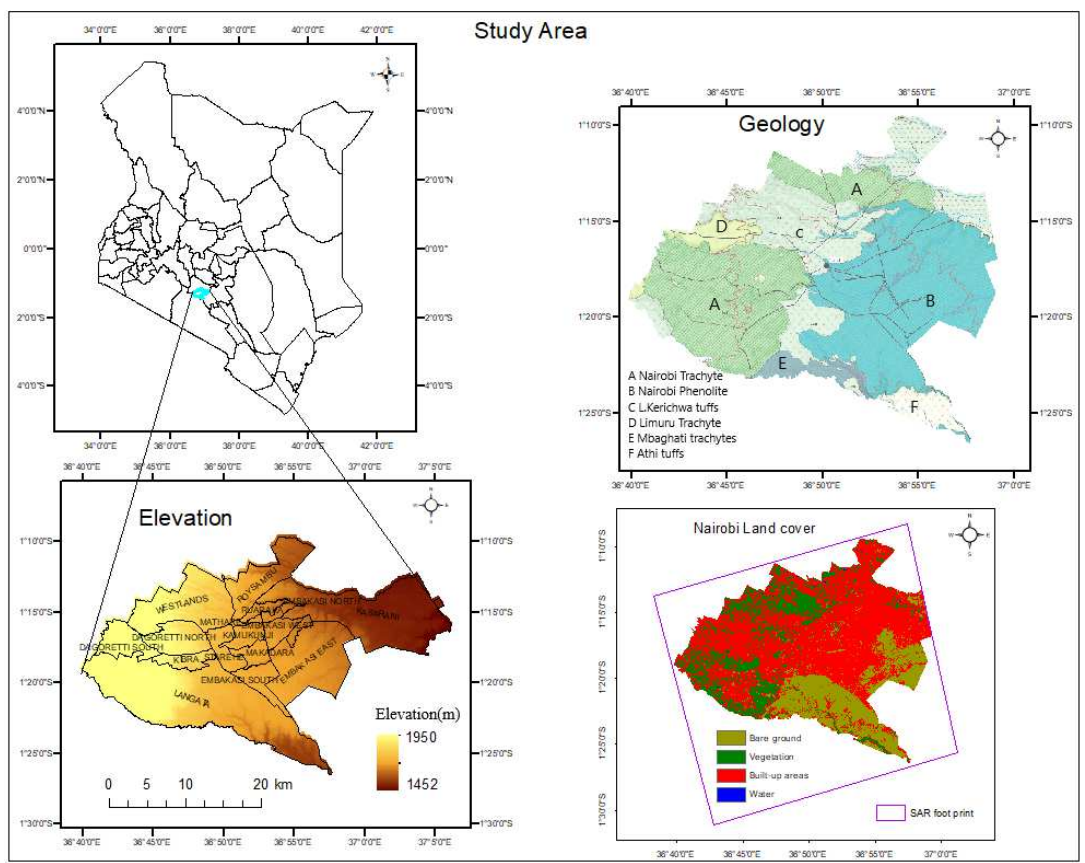

Fig. 1 Location of the study area its elevation, related geology and Land cover clipped to the footprint of the Sentinel 1 ascending orbit

\subsubsection{Sentinel 1 data}

The study uses Sentinel 1 C-band data from the European space agency (ESA). Sentinel 1A was launched in April 2014 but earlier observations within the study area were characterized by huge gaps that made it unsuitable for multi-temporal InSAR MTI analysis. Consistent observations were only realized after the launch of Sentinel 1B in April 2016. It guaranteed consistent observations and decreased the revisit time to 12 days from the earlier 24 days. The Sentinel 1 data are acquired in interferometric wide (IW) mode and each image consists of 3 sub swaths that can act as an independent image. IW is imaged through ScanSAR mode called Terrain Observation with Progressive Scan (TOPS) that aims to improve uniform Signal to Noise Ratio (SNR). The product is distributed with a swath of $250 \mathrm{~km}$ with a resolution of $5 * 20$ in range and azimuth respectively (Geudtner et al., 2014). Table 1 presents a summary of the data used. 
Table 1 Summary of the Sentinel 1 SAR data

\begin{tabular}{lll}
\hline & Ascending & Descending \\
\hline Number of Images & 127 & 99 \\
Relative Orbit & 130 & 79 \\
Track number & 1173 & 597 \\
\hline
\end{tabular}

\subsection{ALOS PALSAR 1}

Advanced Land Observing Satellite(ALOS), PALSAR L-band SAR was launched in May 2006 and operated until 2011 by the Japan Aerospace Exploration Agency (JAXA). For our study area, 13 images were available from July 2007 to October 2010 characterized by inconsistent revisit time. The data was acquired from ESA ALOS PALSAR Dissemination Service in a raw format both single polarization (FBS) and dual-polarization (FBD). Both acquired in ascending mode along path 566 with a spatial resolution of $10 \mathrm{~m}$.

\subsubsection{Groundwater level data}

The location of boreholes within Nairobi County was obtained from Water Resources Authority (WRA). The authority tasked with the management and issuance of permits for groundwater abstraction. Nairobi County falls within the Nairobi Aquifer System (NAS), The NAS data were subset to get the data within the study area. Fig. 2 shows the spatial distribution of boreholes and temporal evolution. A total of 1185 boreholes were found to fall within the study area, the data covers a period of 1930-2018. It should be noted that the number of boreholes presented is underestimation of the actual number of boreholes. The exact number of boreholes in Nairobi is not known but estimated to be above 5000, different studies reporting different estimates due to illegal borehole drilling (Nato, 2015). Chakava et al. (2014) reported that surveys conducted by WRA in 2011 found the number to be 2139 boreholes which was still a gross underestimation. The current number of boreholes could be more than 5000 given that each day, WRA receives an average of five boreholes applications per day at Nairobi sub-region Office Oiro et al. (2020) not considering the illegal borehole drilling. Previous studies are however in agreement that, the number of boreholes has been on the rise, with an exponential increase during the last two decades characterized by decreases in the water table. The boreholes are concentrated in the built-up areas specifically residential areas.

\subsection{InSAR Processing}

\subsubsection{Sentinel 1 Processing}

The interferometric synthetic aperture radar Scientific Computing Environment (ISCE) was used to generate stack focused SLC images. Coregistration was carried out following the Network-Based Enhanced Spectral Diversity approach (Fattahi et al., 2016) which ensures higher accuracy required for images acquired in TOPS mode to avoid phase discontinuities (Prats-Iraola et al., 2012). The SLC stack was then preprocessed to generate interferograms needed for multi-temporal analysis. Interferometric pairs were chosen to minimize 

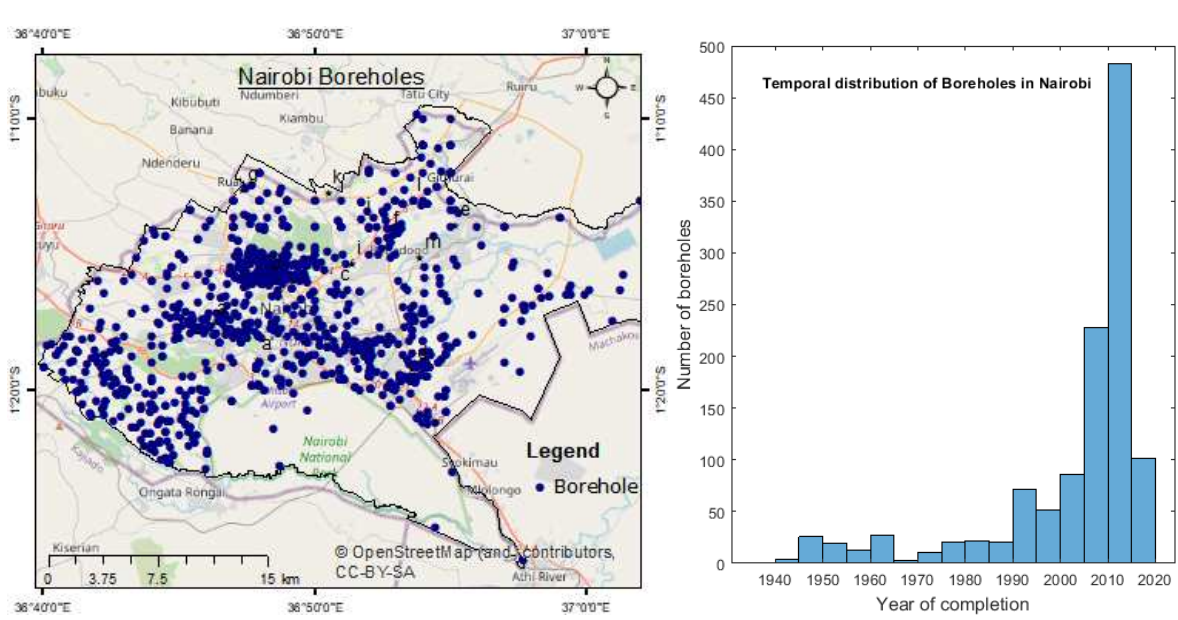

Fig. 2 Spatial and temporal distribution of boreholes within Nairobi county for the period 1930-2018

the geometric and temporal baselines which can easily be achieved because of the short revisit time of Sentinel 1 data and the orbital tube that ensures that the geometric baselines are constrained.The SBAS network adopted for this study is shown in Fig. 3. For MTI we adopted the modified SBAS Hooper (2008) implemented in the Stanford Method for Persistent Scatterers/Multi-Temporal InSAR (StaMPS/MTI) package. It works on single look complex interferograms to select slowly decorrelating filtered phase pixels instead of the multi looked interferograms as implemented in the conventional SBAS (Berardino et al., 2002). The scatters are initially selected based on the amplitude dispersion difference $D_{\Delta, A}$ which is defined as,

$\mathrm{D}_{\Delta, A}=\frac{\sqrt{\frac{\sum_{i=1}^{N}\left(\left|m_{i}\right|-\left|s_{i}\right|\right)^{2}}{N}}}{\frac{1}{2 N} \sum_{i=1}^{N}\left|s_{i}\right|}=\frac{\delta_{\Delta, A}}{\mu_{\Delta, A}}(1)$

Where $N$ is the number of images, $S_{i}$ and $M_{i}$ are the amplitudes of the slave and master, so that $\delta_{\Delta, A}$ is the standard deviation of the difference in amplitude between master and slave and $\mu_{\Delta, A}$ is the mean amplitude. For this study amplitude dispersion index of 0.4 was chosen. The spatially correlated components present in the interferograms are estimated through bandpass filtering while the spatially uncorrelated components are separated through correlation with baseline. The subtraction leaves out the decorrelation noise which is quantified as a temporal coherence expressed as,

$\gamma_{x}=\frac{1}{N}\left|\sum_{i=1}^{N} \exp \sqrt{-1}\left(\psi_{x, 1}-\tilde{\psi_{x, 1}}-\Delta \tilde{\phi}_{\theta, x . i}\right)\right|(2)$

Where $\psi_{x, 1}$ is the wrapped phase, $\psi_{x, 1}$ is the spatially uncorrelated term and $\Delta \tilde{\phi}_{\theta, x . i}$ is the spatially correlated terms. The interferograms were then corrected for spatially-uncorrelated look angle error then it was finally unwrapped using the approach proposed by (Hooper, 2010), a 3D cost function unwrapping algorithm. The tropospheric delay was estimated through time series filtering. The procedure was repeated for both the ascending and ascending data. To determine the nature of the deformation signal, the velocity estimates from 
both the orbits were combined to estimate the vertical and east-west components. The velocity estimates were first interpolated into a regular grid to ensure that pixels are present in both the tracks and cover similar extents. The vertical component and the east-west component was determined following equation 1 . The North-South component was not determined due to the low sensitivity of InSAR measurements in the north-south direction.

$$
\left[\begin{array}{c}
\cos \theta_{a s c}-\sin \theta_{a s c} \cos \alpha_{a s c} \\
\cos \theta_{d s c}-\sin \theta_{d s c} \cos \alpha_{d s c}
\end{array}\right]\left[\begin{array}{l}
d_{v} \\
d_{E}
\end{array}\right]=\left[\begin{array}{l}
d_{l o s_{a} s c} \\
d_{l o s_{d} s c}
\end{array}\right]
$$

Where $\theta$ is the incidence angle and $\alpha$ is the heading angle of the satellite, $d_{v}$ is the movement in a vertical direction while $d_{E}$ is the movement in the horizontal direction. Due to varying nature of the look angle of the Sentinel 1, we used the incidence angle for each of the pixel location in determining the vertical and horizontal components.

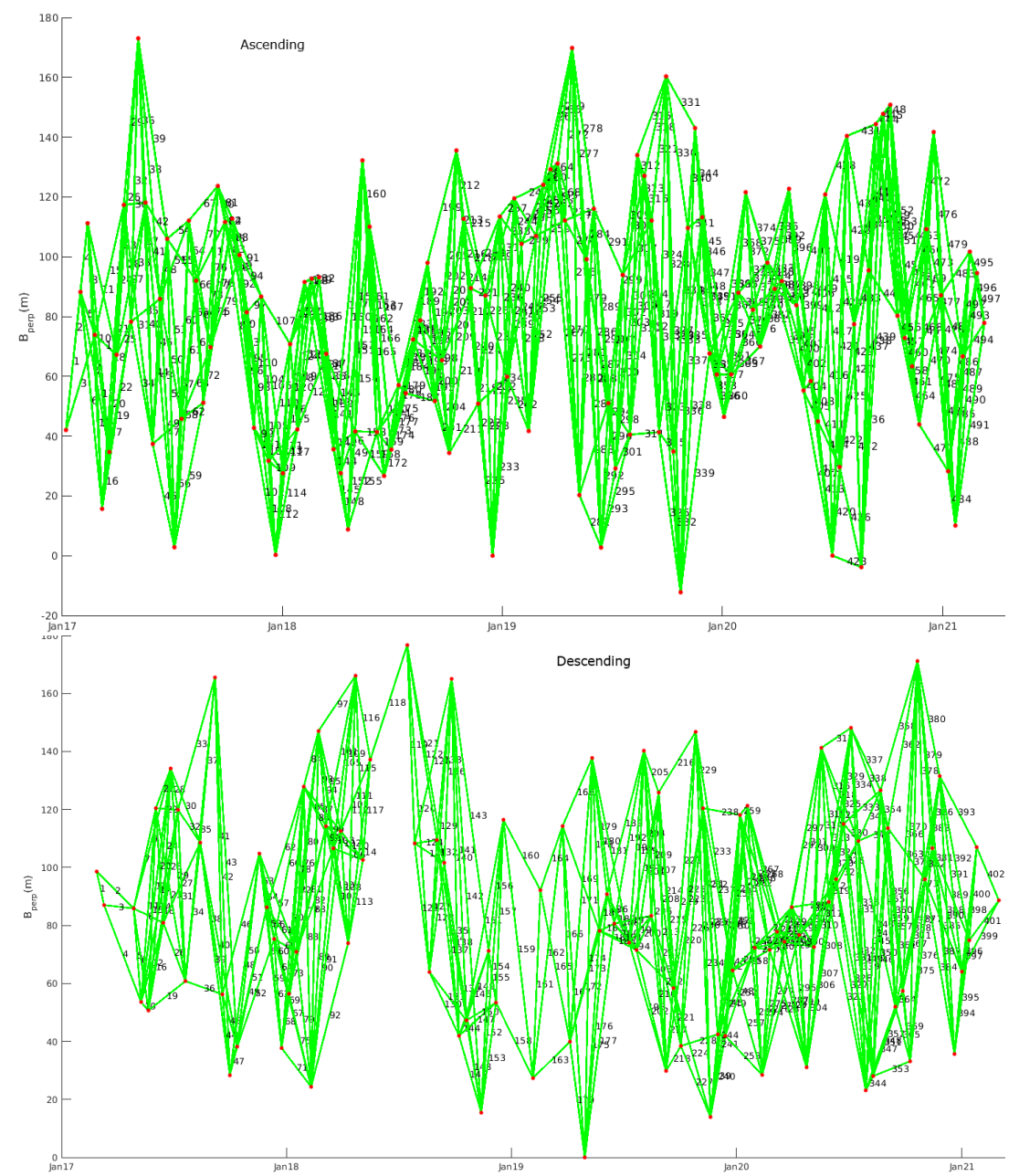

Fig. 3 SBAS network for ascending and descending orbit for Sentinel 1 data 


\subsubsection{ALOS InSAR Processing}

We also used data from ALOS Palsar 1 L-band data for the period 2007-2010. 12 images from the ascending mode,co-polarized data from both FBS and FBD modes were used. Envi Sarscape(Sahraoui et al., 2006) was used to convert the raw ALOS images into single look complex images and for the SBAS time series processing in this study. A small baseline network was generated considering that all the images were connected into the network Fig. 4, given the longer baselines for L-band data, it is least affected by geometric decorrelation (Sandwell et al., 2008), also our study area is majorly composed of build-up areas hence longer temporal baselines are still appropriate for this region. Multi look interferograms were generated, filtered using the Goldstein filter(Goldstein and Werner, 1998) to increase the noise to signal ratio and unwrapped through Minimum Cost Flow (MCF). The 90 m Shuttle Radar Topography Mission (SRTM) DEM was used to remove the topographic influence. The interferograms were then refined to remove orbital errors through the polynomial fitting of degree 3 using the ground control points. Atmospheric noise was then estimated and accounted through time series filtering. The deformation rate inversion was determined assuming vertical direction based on the results of the Sentinel 1 analysis.

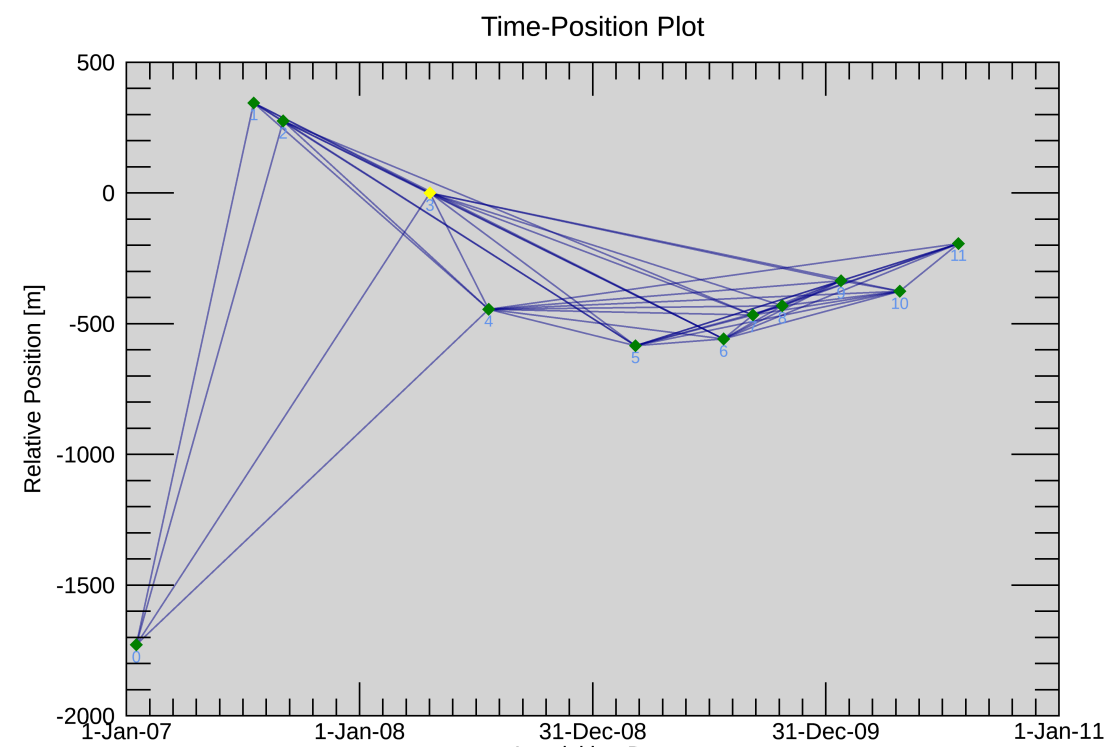

Fig. 4 SBAS network for ALOS PALSAR data

\subsection{Borehole data processing}

Time series analysis for borehole data was carried out to check the variation of the water rest levels (wrl) from the year 1927-2018. For each year we picked the maximum value of wrl within the mapping unit to represent the wrl for that particular year as shown in Fig. 5. To determine the correlation of the water abstraction and the deforming regions, we analyzed the trend of the wrl. Though the two data sets do not overlap in terms of acquisitions time, the rate of change in water rest levels which is spatially varying can show the correlation 
between the deforming region and the groundwater abstraction. The borehole data were also superimposed to the velocity estimates map to check the spatial distribution and its relation to the subsiding regions. Due to the mismatch of the two data sets, correlation analysis was carried out using the water rest levels for the year 2015-2018 and the estimated velocity rates from the InSAR estimates.

Time Series of wrl

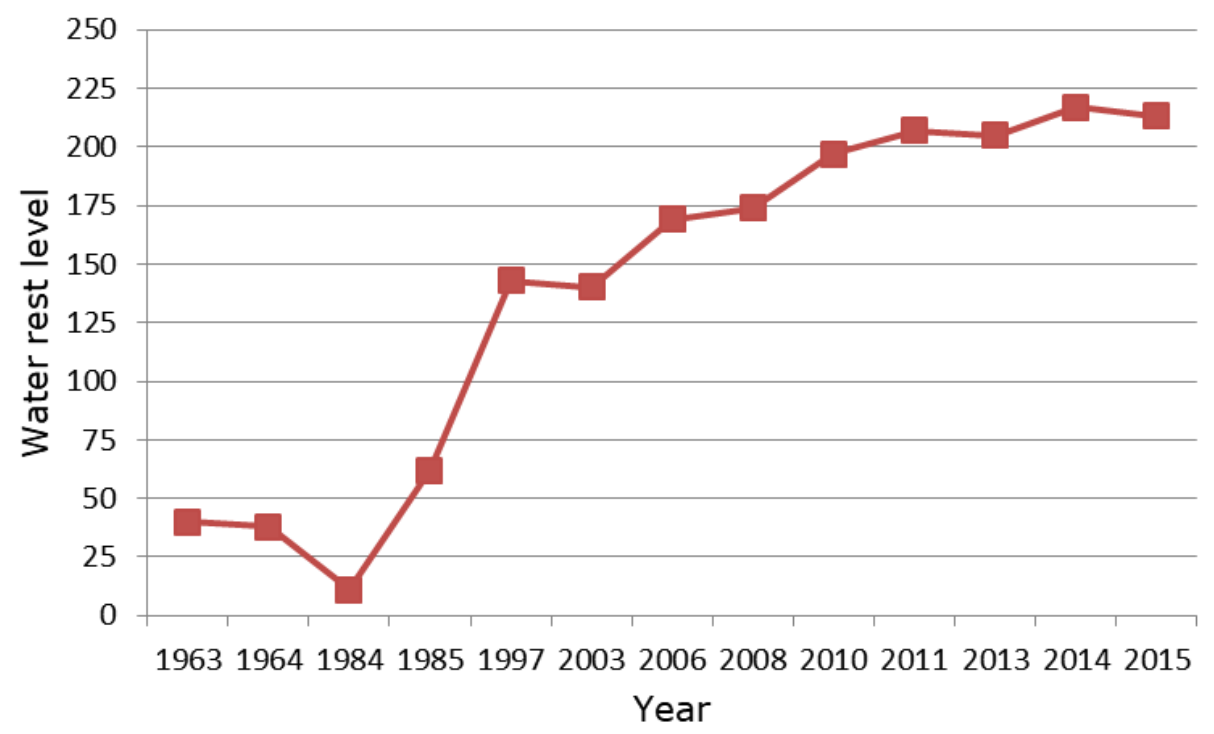

Fig. 5 Temporal variation of the water rest level for Langata, west of Nairobi.

\section{Results}

3.1 Rates of subsidence and spatial pattern for Period of 2007-2010

From the SBAS processing of ALOS data, several locations were observed to subside as shown in Fig. 6. The highest rate of subsidence is recorded at an industrial site, North East of Nairobi (point $\mathrm{f}$ ) at the rate of approx. $47 \mathrm{~mm} / \mathrm{yr}$, other significant deforming regions are also observed at Ngara estate off Moi airbase airport point (point c) at a rate of $30 \mathrm{~mm} / \mathrm{yr}$, Kibera(point a') at a rate of $35 \mathrm{~mm} / \mathrm{yr}$, Upperhill (point a) at a rate of $19 \mathrm{~mm} / \mathrm{yr}$, Westlands at the rate of $14 \mathrm{~mm} / \mathrm{yr}$, Mathare North estate at a rate of $17 \mathrm{~mm} / \mathrm{yr}$ (point i) . All the deforming regions are located in built-up areas and based on their spatial extends it can be treated as localized deformations. 


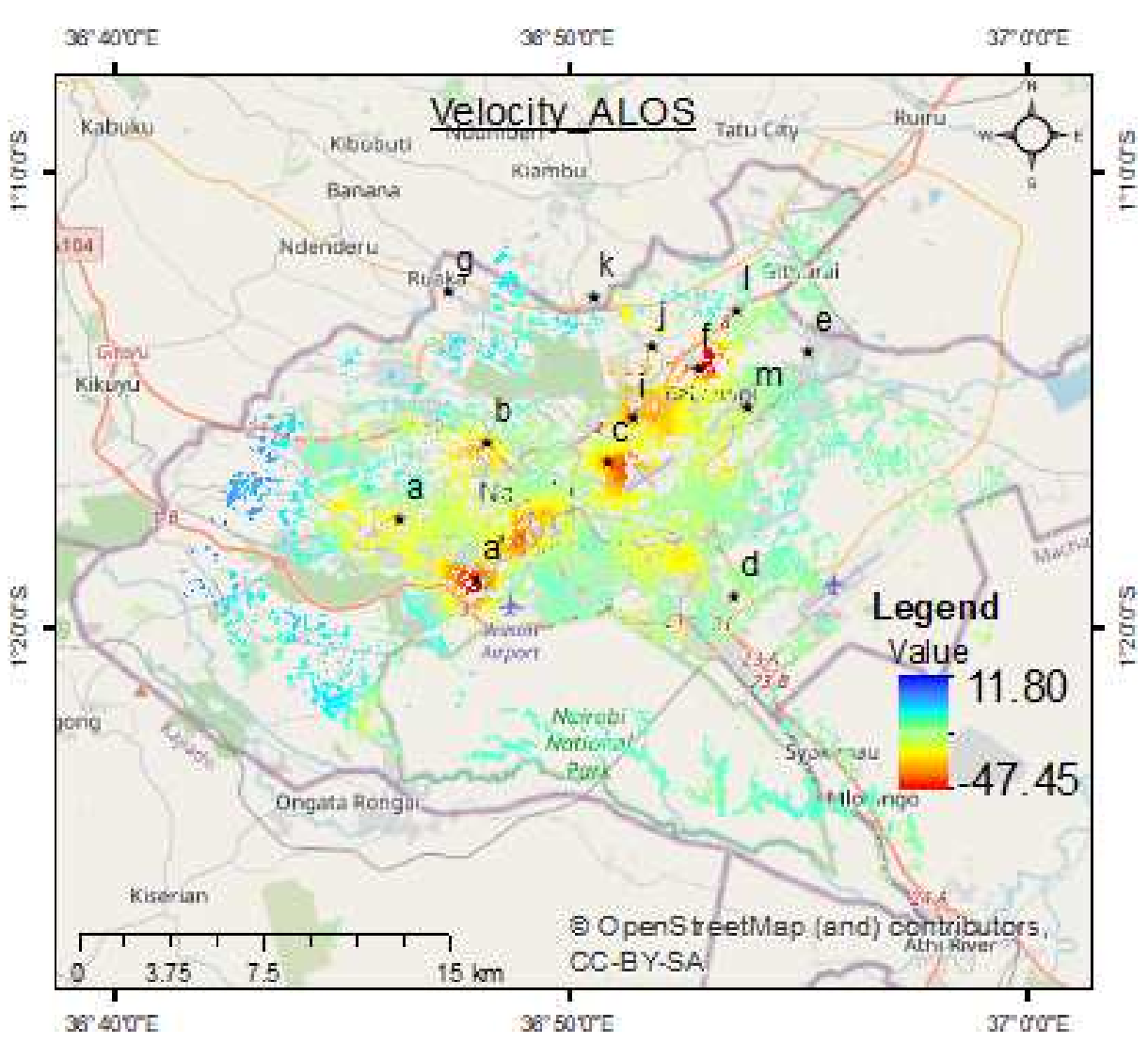

Fig. 6 The LOS Velocity estimates derived from ALOS processing for the year 2007-2010

\subsection{Rates of subsidence and spatial pattern for Period of 2017-2021}

Based on Sentinel 1 processing from both the ascending and descending orbit, several locations were also identified as subsiding with additional new sites identified as subsiding. The LOS estimates from both the ascending and descending orbits show consistent spatial patterns and magnitude for the locations experiencing significant subsidence. The correlation of velocity estimates from the ascending and descending orbits is shown in Fig. ?? . The highest rate of subsidence is registered in the west of Nairobi (region aa') with an approximate value of approx. $48 \mathrm{~mm}$ /year. It is located within a region with the largest areal deformation, the region comprises part of Langata, Kibera and Upperhill, the deforming region, unlike other subsiding locations, is large covering an area of approximately 2000ha. Other regions that exhibit significant deformations are residential estates that include Mathare North stretching to Garden estate (region ijk), Westlands near Consolata shrine stretching to parklands (point b), Ngara estate off Moi Airbase airport point (point c), Kasarani estate stretching to Roysambu (region ei), Fourways Junction Mall(point k), and Ruaka near Two Rivers Mall(point g), in Fig. 7. Additionally, other localized deformations are recorded in East of Nairobi near Fedha estate (point d) and at the edges of Dandora landfill (point m) which is the third-largest landfill in Africa, deformation is not recorded at the landfill itself due to low coherence attributed to changing surface characteristics of the dumpsite that is 

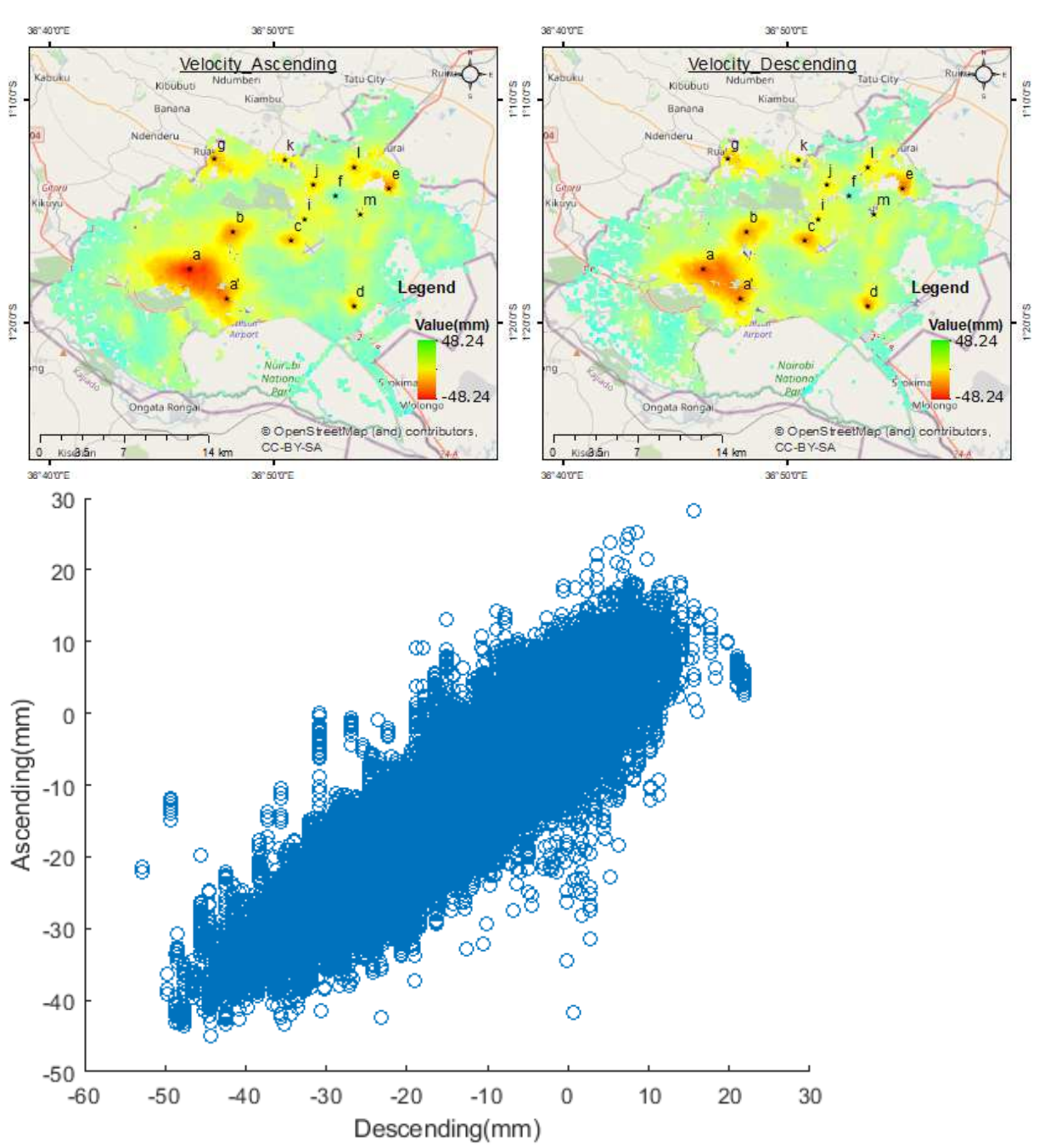

Fig. 7 The LOS velocity estimates from the ascending(a) and descending(b) processing of Sentinel 1 data clipped to the footprint of ascending track and their correlation()

still active. Aside from those locations that are experiencing subsidence, it can be generally observed that most of the parts in Nairobi do not experience any deformation, the uplift recorded is isolated and can be regarded as outliers as shown in the scatter plot matrix in Fig. 7. Other regions

\subsection{Comparison for 2007-2010 and 2017-2021}

The comparison of the spatial pattern and rates of deformation for the two observations periods show mixed results. There exist locations, namely Westlands(poin b), Ngara(point c), Kibera-upperhill(section aa') that subsidence was witnessed during the two observations periods, The difference being an increase in the spatial extent and rates of the deforming re- 
gions. Additionally, it can be observed that the spatial extent of the two subsiding regions(b and aa') have exponentially increased, and given the same trend, the two deforming units could merge. We also observed that from 2017 to 2021, new subsiding locations with considerably high deformation rates were observed that were not recorded during 2007-2010 period. The locations include Embakasi near Fedha estate(point d), Kasarani(point e) and Ruaka (point g). The three locations were not previously occupied but now serve as residential estates, we show for instance by use of google images the temporal ocuupation of location e in Fig. 8 . Another notable observation is point $\mathrm{f}$ that falls within premises of East African Breweries Limited(EABL) it was previously deforming at the highest rate for the period 2007 to 2010 but recorded insignificant deformation for the period 2017 to 2021. The average rates of velocity have increased for all the subsiding locations as shown in table 2. It should however be noted that for the period 2007-2010 the SBAS network is not robust enough compared to the Sentinel 1 network due to the limited number of ALOS images. The fact that the two sets of data show some consistent spatial pattern of deformation further reinforces that there exist locations that are significantly subsiding.

Table 2 comparison of LOS velocity estimates

\begin{tabular}{lll}
\hline Point & $2007-2010$ & $2017-2021$ \\
\hline $\mathrm{a}$ & -5.79 & -47.79 \\
$\mathrm{~b}$ & -9.41 & -31.29 \\
$\mathrm{c}$ & -11.62 & -27.1 \\
$\mathrm{~d}$ & 1.2 & -22.76 \\
$\mathrm{e}$ & -0.87 & -32.48 \\
$\mathrm{f}$ & -36.63 & 5.95 \\
$\mathrm{~g}$ & & -26.5 \\
$\mathrm{i}$ & -14.24 & -17.02 \\
$\mathrm{j}$ & -13.08 & -19.06 \\
$\mathrm{k}$ & 4.01 & -17.37 \\
$\mathrm{l}$ & -15.08 & -22.47 \\
$\mathrm{~m}$ & -4.72 & -10.97 \\
\hline
\end{tabular}
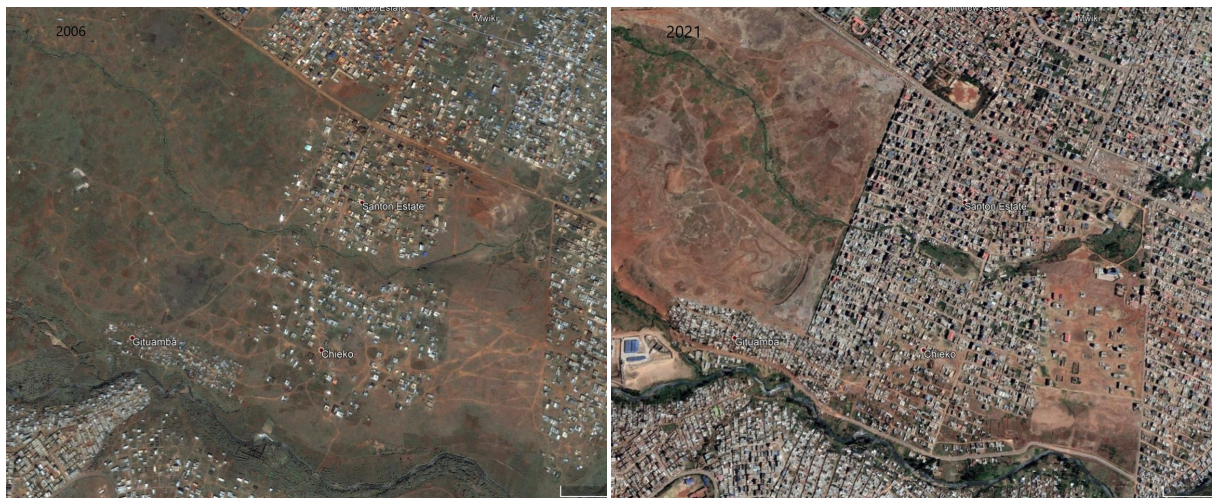

Fig. 8 Google Earth images for the year 2006 and 2021 for point e on Fig. 6 

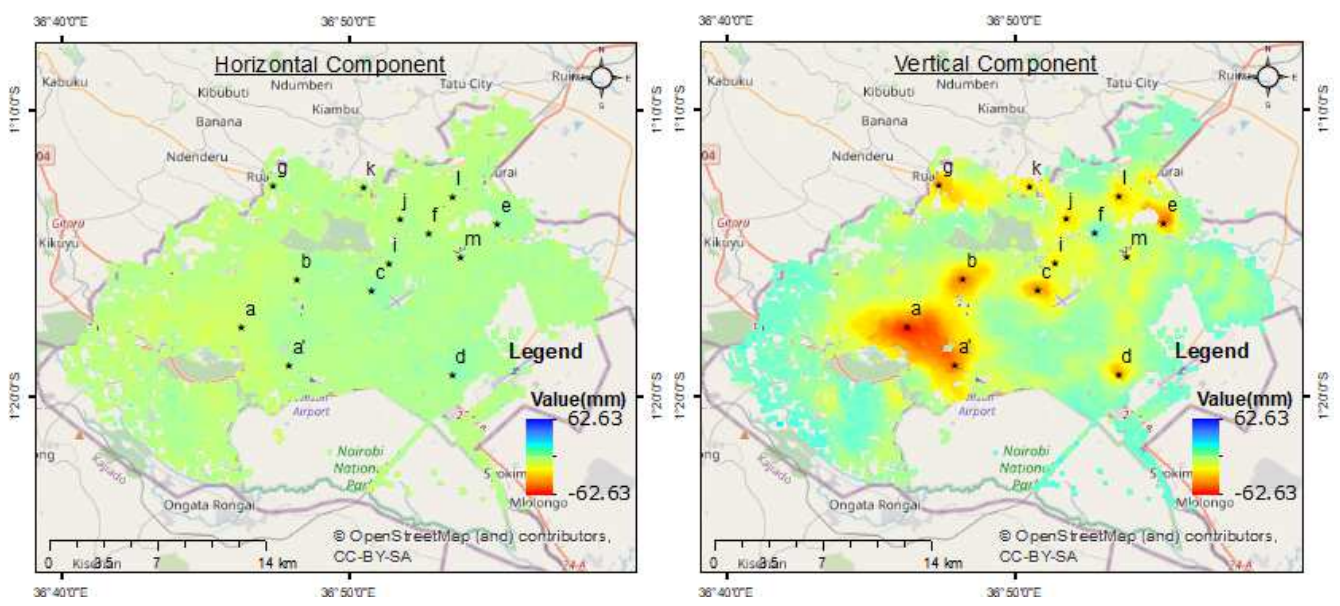

\subsection{Direction of subsidence}

The direction of deformation is majorly vertical based on the combination of the LOS estimates from ascending and descending orbit of Sentinel 1 data as shown in Fig. 9. The lateral deformation is insignificant, its estimates are in the range of the accuracy of LOS estimates with no particular pattern. Except for some locations within point aa' that recorded the highest deformation that could be interpreted as the consequence of intense subsidence recorded in this region that might might have caused horizontal movement.

Fig. 9 Velocity estimates of horizontal and vertical components .

\subsection{Time series analysis}

The nature of subsidence is majorly linear for the subsiding locations except for some locations that show varying rates of subsidence where the deformation has since stopped or subsidence has since occurred. We have shown in Fig. 10 the time series displacement rates for the selected points that capture the scenarios explained above. As observed in Fig. 6 and Fig. 7 location a has been subsiding during both observation periods, with higher rates being observed in 2017-2021. Location $\mathrm{f}$ which was the most deforming during 2007-2010 has stabilized between 2017 and 2021. Additionally, we noticed two locations that were not deforming during 2007-2010 and are now subsiding, namely region $\mathrm{d}$ and e, region $\mathrm{d}$ started to subside towards the end of the year 2010 and has been constantly derforming. However point $\mathrm{e}$ is the most recent deforming location where deformation is being realized towards mid of the year 2019. We note that there is a gap of seven years and to understand the deformation that occurred in between the two periods. We have processed Sentinel 1 interferograms from the descending orbit for the 11. April 2014 to 27 February 2017 and 27 February 2017 to -20. December 2020. Given that the study area is urban and the orbital tube of Sentinel 1 leading to short geometrical baselines, the coherence of most of the parts is still high for the longer temporal baselines interferograms. From the interferograms, it can be observed that the regions that were recorded to have experienced subsidence in MTI analysis match with those of the interferogram as shown by the concentric circles of the wrapped interferogram in Fig. 11. For fifteen months cumulative subsidence of 21.38 radians was recorded which 

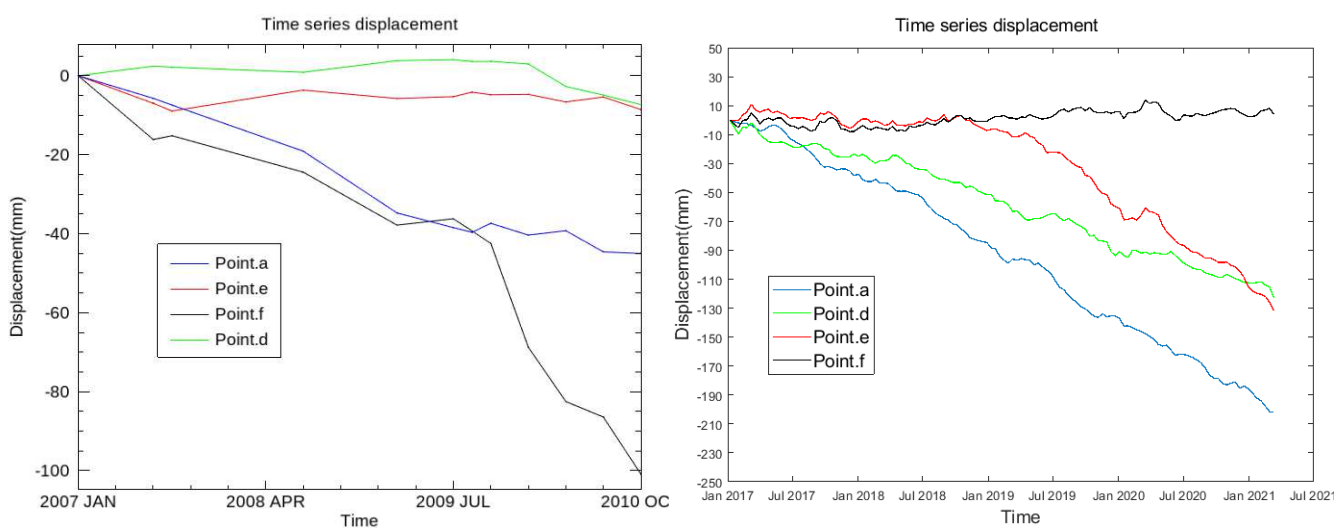

Fig. 10 Time series displacement of some selected points on Fig. 6 for 2007-2010 and 2017-2021.

is approximately $95 \mathrm{~mm}$, implying that those regions have been subsiding at almost equal rates. It can also be observed that point e started subsiding after the year 2017. It can also be observed that Ngara estate point $\mathrm{C}$ was initially deforming at a faster rate compared to other regions but the rate has reduced in comparison with other places. The shape of the largest deforming site $\mathrm{A}$ is in the orientation of Nw-SE elongated and with the trend, it appears that there exists the possibility of the two deforming regions aa' and b merging as unit deforming areas.

\section{Discussion}

\subsection{Groundwater exploitation as a driver of subsidence}

The spatial pattern of most of the subsiding regions coincides with the locations that have been reported to experience a decrease in the water table. The coefficient of determination between the groundwater level and the velocity estimates is 0.48 as shown in Fig. 12 but it should be noted that the water levels are for the year 2015 to 2018 which is outside the observation period of our study. It shows the contribution of groundwater over-exploitation in the depletion of the aquifer and the consequent subsidence due to a reduction in the pore pressure within the aquifer system. Some of the locations cited to be settling in Nairobi by Mathu et al. (2014), though difficult to compare with our estimates because they were not spatially presented, coincide with the subsiding regions from our estimates. Moreover, the subsiding regions have been found to have higher rates of decrease in water table levels compared to other regions in Nairobi. For instance, some section of region aa' in Fig. 7 with the highest rate of subsidence falls in Langata, a region that has the highest number and density of boreholes characterized by a decrease in the water table at higher rates compared to other places within Nairobi county as noted by Nato (2015) and Ochungo et al. (2019). Chakava et al. (2014) report that this region experiences a water table level decline of $7 \mathrm{~m}$ per year compared to other regions that decline at the rate of $3 \mathrm{~m}$. Additionally, EABL(location $\mathrm{f}$ ) installed a water recycling plant towards the end of the year 2007 which has greatly reduced the water demand (Wakhungu et al., 2017; EABL, 2011) and explains why subsidence is not recorded between 2017-2021. The intense subsidence recorded during 2007-2010 could be associated with huge demand of water during this period due to the nature of the process- 

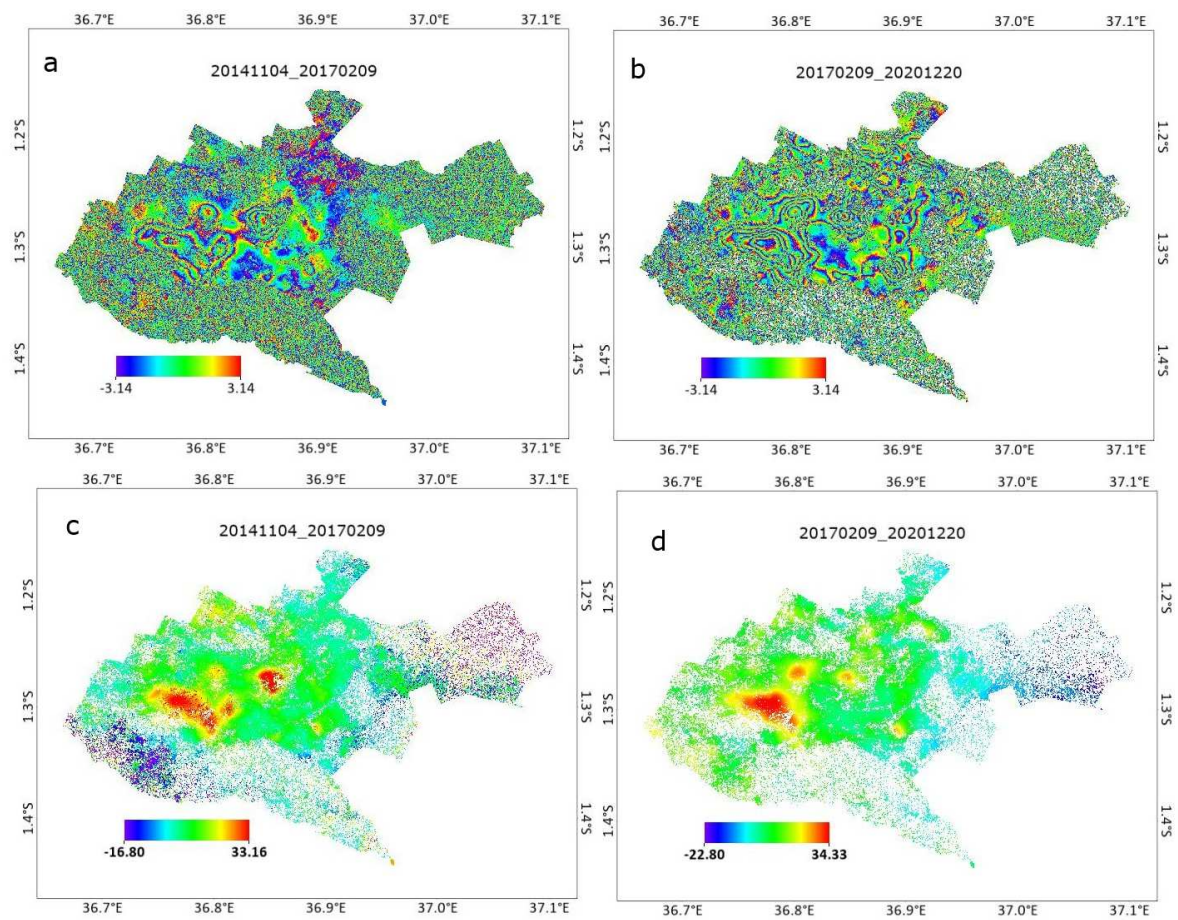

Fig. 11 Wrapped(a and b) and unwrapped(c and d) interferograms for 20141104-20170209 and 2017020920201220 estimated from Sentinel 1 descending orbit showing the evolution of the deforming units.
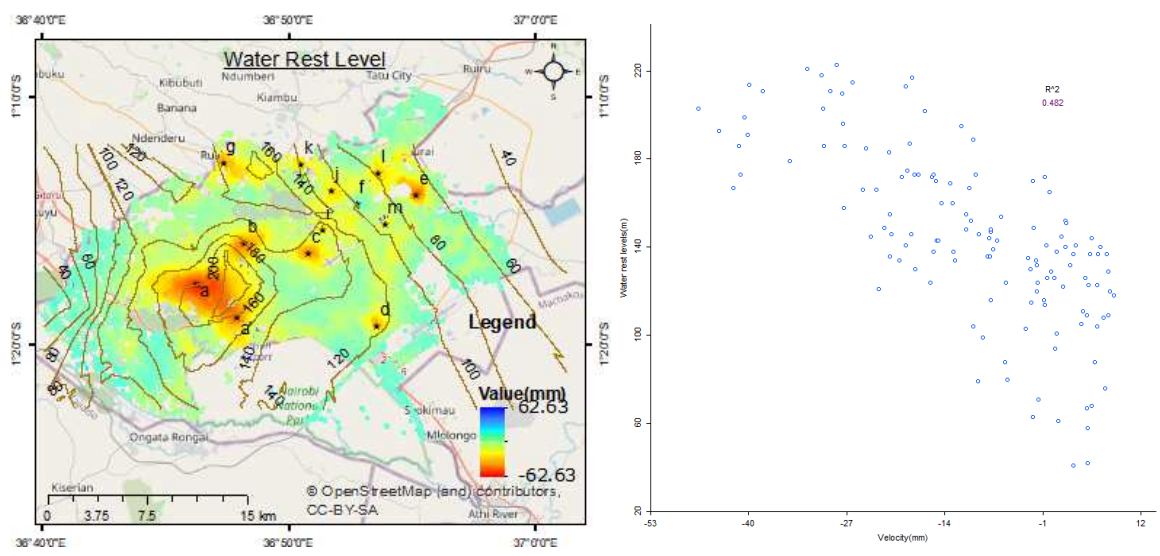

Fig. 12 Water rest level contours for the period 2015-2018 superimposed on velocity estimates

ing which requires alot of water. Most of the boreholes are constructed by the residential owners to supplement the inconsistent supply of water hence the reason why most of the subsidence is witnessed in the residential areas. Moreover, location (e) in figure 4 is a developing residential area that was not previously densely occupied as can be seen in figure 8 no deformation was recorded for the period 2007-2010, the region starts to deform mid-2019 
as shown in the figure. We do not have borehole data at this location but given the norm of the new buildings supplementing piped water with Groundwater, it can be hypothesized that the recently subsiding region is attributed to water abstraction as a result of a change in land use to residential as shown in figure 6. Analysis of the time series of the displacement rates show a linear trend with no periodic change, this shows that a major component of subsidence is due to the inelastic settlement which is in agreement with the hydrogeological modelling of Mathu et al. (2014).

4.2 Other causative agents

There exist deforming locations that can not be linked to overexploitation of underground water, for instance, location a' which was found to deform during both the observations period lies within the flood plain of River Ngong. The region is the largest informal settlement in Kenya with an approximate population of 300,000 (Ndemo, 2020; Ren et al., 2020). It was previously marshland land (Ngugi et al., 2012) and has been known to flood (Mulligan et al., 2016). The subsidence at this location is due to consolidation as a result of the construction of congested unplanned structures on the floodplain. Fig. 13 shows th location of the subsiding unit in relation to the flood plain.Another interesting subsiding region that cannot be solely tied to groundwater exploitation is location $\mathrm{d}$, the spatial extend of the subsiding unit is limited and the adjacent residential units are not subsiding, moreover, the water rest levels at this region are shallow compared to other regions. The residential units at this location consist of high rise buildings built close to each other, with each building hosting a large number of tenants(Mwau, 2019). Subsidence at this location could be attributed to consolidation due to the loading effect of the buildings. As it can be observed in Fig. 6 the region was not subsiding during the period 2007-2010, the deformation thereafter can be attributed to loading associated with the high-density of high-rise buildings that were constructed after the year 2007. 


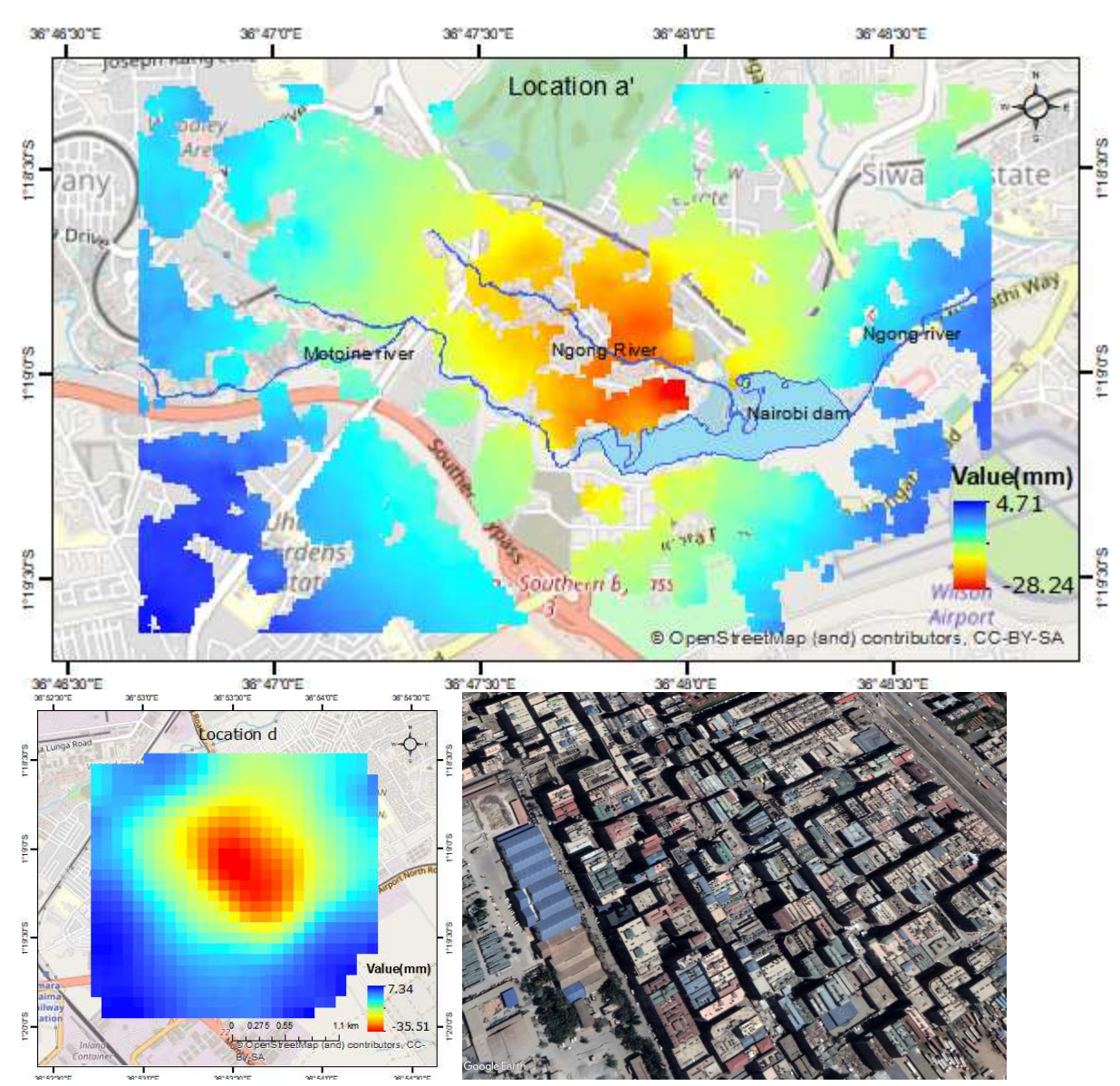

Fig. 13 Velocity estimates for region a' and its relation to the Ngong river flood plain and velocity estimates of point $\mathrm{d}$ and its relation to building density, image courtesy of Google.

The phenomenon is consistent with other studies that have reported localized subsidence attributed to the higher density of buildings (Xu et al., 2012; Yang et al., 2018)). Additionally, the deformation observed at the edges of Dandora landfill(location $\mathrm{m}$ ) can be attributed to consolidation and the biochemical process, similar observations have been noted in other places like the case of Baek et al. (2019), the continued filling of the waste poses danger to the neighbouring properties. Similarly, the recent major developments in the Noth west of Nairobi on the previously undeveloped land seems to have triggered subsidence, for instance, the development of the Two Rivers Mall and the subsequent developments within its environs could be attributed to the subsidence at location $\mathrm{g}$. The subsidence witnessed at the two airports (Wilson Airport and Moi Airbase, Eastleigh airports ) can be attributed to foundation settlement that is tied to the consolidation of the filling material during construction and the loading effect during take-off and landing. Subsidence due to takeoff and landing of planes has been reported in other cities (Aobpaet et al., 2013; Gao et al., 2016; Mesri and Funk, 2015). Precise deformation monitoring though currently lacking could in future provide major insights on the deformation at these two airports. This is due to the 
fact the two airports are located off the two subsiding regions aa' and $\mathrm{c}$ and the deformation recorded could be also be attributed to the effect of adjacent deformation.

\section{Conclusion}

We have shown that indeed the fear of possible subsidence in Nairobi that had been earlier postulated exists. The research findings empirically collaborate with previous hydrological studies that had suggested a possibility of land subsidence in Nairobi. We have quantified the subsidence spatially showing five deforming regions. The subsidence is of higher magnitude in the largest deforming area with a velocity of $60 \mathrm{~mm} / \mathrm{year}$. The subsidence in most of the locations has been gradually occurring linearly and the nature of deformation is vertical. The subsidence can be attributed to over exploitation of groundwater although subsidence tied to consolidation due loading of the buildings,landfill and developmentsalong Ngong river flood plain also exist. A deformation map is an important geodetic tool for guiding mitigation measures to prevent further subsidence and avoid the destruction of property. For regions that experience subsidence due to over exploitation of groundwater, the map can be used to guide issuing of licenses for drilling or stopping further abstraction. Moreover, the map provides an empirical way for locating the observation wells for monitoring the groundwater levels to provide a true representation of the depletion of the aquifer. The impact of subsidence of the estimated magnitude could lead to the destruction of property and life. The building permits for the construction and the building codes can also benefit from the deformation map by taking into account the expected subsidence. Engineering projects that depend on geodetic control need to be aware of the possibility of significant deformation, especially for the projects that depend on elevation differences for design. Cumulative subsidence of approximately $30 \mathrm{~cm}$ over a four year period can significantly alter the structural integrity of sewer lines and drainage networks that depend on gradient flow leading to instances of flow back and or flooding. Given that SOK does not update the geodetic network it implies that vertical geodetic controls that fall within the subsiding locations have been rendered unreliable. InSAR has reversed how geodetic measurements are conducted, instead of using higher resolution geodetic measurements followed by InSAR; it is now common to start with InSAR then high-resolution techniques targeted at already identified deformed areas(Liao et al., 2020). Hence future research will be geared towards hydrogeological modelling with higher resolution geodetic techniques such GNSS or high-resolution InSAR for multi-sensor monitoring for regions identified as deforming. Given the significance of Nairobi to Kenya economy, measures have to be taken to mitigate the effects of recorded subsidence.

Acknowledgements We acknowledge the ESA for providing Sentinel 1 data through the ASF vertex portal and ALOS Palsar data via ESA online Dissemination Service. We also wish to thank Mr Geofrey Gichuru for the assistance in ground-truthing

\section{Conflict of interest}

223 The authors declare that they have no conflict of interest. 


\section{References}

Abidin HZ, Andreas H, Gumilar I, Fukuda Y, Pohan YE, Deguchi T (2011) Land subsidence of Jakarta (Indonesia) and its relation with urban development. Natural Hazards 59(3): 1753

Aobpaet A, Cuenca MC, Hooper A, Trisirisatayawong I (2013) InSAR time-series analysis of land subsidence in Bangkok, Thailand. International Journal of Remote Sensing 34(8):2969-2982

Argyrakis P, Ganas A, Valkaniotis S, Tsioumas V, Sagias N, Psiloglou B (2020) Anthropogenically induced subsidence in Thessaly, central Greece: new evidence from GNSS data. Natural Hazards 102(1):179-200

Baek WK, Jung HS, Jo MJ, Lee WJ, Zhang L (2019) Ground subsidence observation of solid waste landfill park using multi-temporal radar interferometry. International Journal of Urban Sciences 23(3):406-421

Berardino P, Fornaro G, Lanari R, Sansosti E (2002) A new algorithm for surface deformation monitoring based on small baseline differential SAR interferograms. IEEE Transactions on geoscience and remote sensing 40(11):2375-2383

Bhattarai R, Alifu H, Maitiniyazi A, Kondoh A (2017) Detection of land subsidence in Kathmandu Valley, Nepal, using DInSAR technique. Land 6(2):39

Chakava Y, Franceys R, Parker A (2014) Private boreholes for Nairobi's urban poor: The stop-gap or the solution? Habitat International 43:108-116

Chaussard E, Wdowinski S, Cabral-Cano E, Amelung F (2014) Land subsidence in central Mexico detected by ALOS InSAR time-series. Remote sensing of environment 140:94106

Chen B, Gong H, Li X, Lei K, Ke Y, Duan G, Zhou C (2015) Spatial correlation between land subsidence and urbanization in beijing, china. Natural Hazards 75(3):2637-2652

Chen C, Pei S, Jiao J (2003) Land subsidence caused by groundwater exploitation in Suzhou City, China. Hydrogeology journal 11(2):275-287

Chrzanowski A, Yong-qi C, Leeman RW, Leal J, Maraven (1989) Integration of the Global Positioning System with geodetic leveling surveys in ground subsidence studies. CISM Journal 43(4):377-386

EABL (2011) Eabl annual report and financial statements 2011. Tech. rep., URL https: //africanfinancials.com/document/ke-eabl-2011-ar-00/

Eriksen HØ, Lauknes TR, Larsen Y, Corner GD, Bergh SG, Dehls J, Kierulf HP (2017) Visualizing and interpreting surface displacement patterns on unstable slopes using multigeometry satellite SAR interferometry (2D InSAR). Remote Sensing of Environment 191:297-312

Ezquerro P, Del Soldato M, Solari L, Tomás R, Raspini F, Ceccatelli M, Fernández-Merodo JA, Casagli N, Herrera G (2020) Vulnerability assessment of buildings due to land subsidence using InSAR data in the ancient historical city of Pistoia (Italy). Sensors 20(10):2749

Fattahi H, Agram P, Simons M (2016) A network-based enhanced spectral diversity approach for TOPS time-series analysis. IEEE Transactions on Geoscience and Remote Sensing 55(2):777-786

Ferretti A, Prati C, Rocca F (2000) Nonlinear subsidence rate estimation using permanent scatterers in differential SAR interferometry. IEEE Transactions on geoscience and remote sensing 38(5):2202-2212

Foster S, Tuinhof A (2005) The role of groundwater in the water supply of greater Nairobi, Kenya. World Bank Case Profile Collection 13 
Gao M, Gong H, Chen B, Zhou C, Chen W, Liang Y, Shi M, Si Y (2016) InSAR time-series investigation of long-term ground displacement at Beijing Capital International Airport, China. Tectonophysics 691:271-281

Gasperini D, Allemand P, Delacourt C, Grandjean P (2014) Potential and limitation of uav for monitoring subsidence in municipal landfills. International Journal of Environmental Technology and Management 17(1):1-13

Geudtner D, Torres R, Snoeij P, Davidson M, Rommen B (2014) Sentinel-1 system capabilities and applications. In: 2014 IEEE Geoscience and Remote Sensing Symposium, IEEE, pp 1457-1460

Goldstein RM, Werner CL (1998) Radar interferogram filtering for geophysical applications. Geophysical research letters 25(21):4035-4038

Guo H, Zhang Z, Cheng G, Li W, Li T, Jiao JJ (2015) Groundwater-derived land subsidence in the north china plain. Environmental earth sciences 74(2):1415-1427

Haregu TN, Ziraba AK, Aboderin I, Amugsi D, Muindi K, Mberu B (2017) An assessment of the evolution of kenya's solid waste management policies and their implementation in nairobi and mombasa: analysis of policies and practices. Environment and Urbanization 29(2):515-532

Hirose K, Maruyama Y, Murdohardono D, Effendi A, Abidin HZ (2001) Land subsidence detection using JERS-1 SAR Interferometry. In: 22nd Asian Conference on Remote Sensing, pp 5-9

Hooper A (2008) A multi-temporal InSAR method incorporating both persistent scatterer and small baseline approaches. Geophysical Research Letters 35(16)

Hu J, Li ZW, Ding XL, Zhu JJ, Zhang L, Sun Q (2014) Resolving three-dimensional surface displacements from InSAR measurements: A review. Earth-Science Reviews 133:1-17

Hudson Hill S (2020) A terrible beauty: Art and learning in the anthropocene. Journal of Museum Education 45(1):74-90

Hung WC, Hwang C, Liou JC, Lin YS, Yang HL (2012) Modeling aquifer-system compaction and predicting land subsidence in central taiwan. Engineering Geology 147:7890

KNBS (2019) Population and Housing Census Report. Tech. rep., URL https://housingfinanceafrica.org/documents/ 2019-kenya-population-and-housing-census-reports/

Liao M, Balz T, Rocca F, Li D (2020) Paradigm changes in surface-motion estimation from sar: Lessons from 16 years of sino-european cooperation in the dragon program. IEEE Geoscience and Remote Sensing Magazine 8(1):8-21, DOI 10.1109/MGRS.2019. 2956176

de Luna RMR, dos Anjos Garnés SJ, Cabral JJdSP, dos Santos SM (2017) Groundwater overexploitation and soil subsidence monitoring on Recife plain (Brazil). Natural Hazards 86(3):1363-1376

Makunda CS (2018) Sustainable housing through sustainable planning practices: Challenges and opportunities for formal housing provision in nairobi, kenya. In: Lifelong Learning and Education in Healthy and Sustainable Cities, Springer, pp 539-549

Matheson FJ (1966) Geology of the Kajiado area. Geological Survey of Kenya Report 70

Mathu EM, Onyancha C, Mwea S, Ngecu W (2014) Effects of drilling deep tube wells in the urban areas of Nairobi city, Kenya

Measurement Systems Limited (????) Muya CORS. URL https : //muya-cors . com/

Mesri G, Funk JR (2015) Settlement of the Kansai international airport islands. Journal of Geotechnical and Geoenvironmental Engineering 141(2):4014102 
Mulligan J, Harper J, Kipkemboi P, Ngobi B, Collins A (2016) Community-responsive adaptation to flooding in kibera, kenya. In: Proceedings of the Institution of Civil EngineersEngineering Sustainability, Thomas Telford Ltd, vol 170, pp 268-280

Mumma A, Lane M, Kairu E, Tuinhof A, Hirji R (2011) Kenya groundwater governance case study

Mwau B (2019) The rise of nairobi's concrete tenement jungle. URL https://goodmenproject.com/social-justice-2/ the-rise-of-nairobis-concrete-tenement-jungle/

Nairobi City Council (2007) City of Nairobi Environment Outlook. Tech. rep.

Nato S (2015) Groundwater Management Practice in Nairobi County

Ndemo B (2020) Slum digitisation, its opponents and allies in developing smart cities: The case of kibera, nairobi. In: Open Cities - Open Data, Springer, pp 129-148

Neelmeijer J, Schöne T, Dill R, Klemann V, Motagh M (2018) Ground deformations around the Toktogul reservoir, Kyrgyzstan, from envisat ASAR and sentinel-1 data-A case study about the impact of atmospheric corrections on InSAR time series. Remote Sensing 10(3):1-21, DOI 10.3390/rs10030462

Ngugi E, Benoit C, Hallgrimsdottir H, Jansson M, Roth EA (2012) Partners and clients of female sex workers in an informal urban settlement in nairobi, kenya. Culture, health \& sexuality $14(1): 17-30$

Ochungo EA, Ouma GO, Obiero JPO, Odero NA (2019) An Assessment of Groundwater Grab Syndrome in Langata Sub County, Nairobi City-Kenya. Journal of Water Resource and Protection 11(05):651

Oiro S, Comte JC, Soulsby C, MacDonald A, Mwakamba C (2020) Depletion of groundwater resources under rapid urbanisation in Africa: recent and future trends in the Nairobi Aquifer System, Kenya. Hydrogeology Journal 28(8):2635-2656, DOI 10.1007/ s10040-020-02236-5, URL https://doi .org/10 . 1007/s10040-020-02236-5

Onyancha C, Dalyot S, Siriba D, Sester M (2012) Modelling of Spatial and Temporal Variations in Groundwater Rest Levels In Nairobi City Using Geographic Information System. Nile Water Science and Engineering Journal, 5 (1) pp 26-33

Onyancha CK, Mathu EM, Mwea SK, Ngecu WM (2011) Dealing with sensitive and variable soils in nairobi city. vol 9:282-291

Otiso KM, Owusu G (2008) Comparative urbanization in ghana and kenya in time and space. GeoJournal 71(2-3):143-157

Pratesi F, Tapete D, Del Ventisette C, Moretti S (2016) Mapping interactions between geology, subsurface resource exploitation and urban development in transforming cities using InSAR Persistent Scatterers: Two decades of change in Florence, Italy. Applied Geography 77:20-37

Prats-Iraola P, Scheiber R, Marotti L, Wollstadt S, Reigber A (2012) TOPS Interferometry With TerraSAR-X. IEEE Transactions on Geoscience and Remote Sensing 50(8):31793188, DOI 10.1109/TGRS.2011.2178247

Rateb A, Abotalib AZ (2020) Inferencing the land subsidence in the nile delta using sentinel1 satellites and gps between 2015 and 2019. Science of the Total Environment 729:138868

Ren H, Guo W, Zhang Z, Kisovi LM, Das P (2020) Population density and spatial patterns of informal settlements in nairobi, kenya. Sustainability 12(18):7717

Sahraoui OH, Hassaine B, Serief C, Hasni K (2006) Radar interferometry with sarscape software. Photogrammetry and Remote Sensing

Sandwell DT, Myer D, Mellors R, Shimada M, Brooks B, Foster J (2008) Accuracy and resolution of alos interferometry: Vector deformation maps of the father's day intrusion at kilauea. IEEE Transactions on Geoscience and Remote Sensing 46(11):3524-3534 
Stamps DS, Nyblade A, Kianji G (2019) Uganda-Kenya Eastern Branch GNSS Network Tosi L, Teatini P, Carbognin L, Frankenfield J (2007) A new project to monitor land subsidence in the northern Venice coastland (Italy). Environmental Geology 52(5):889-898

Ustun A, Tusat E, Yalvac S (2010) Preliminary results of land subsidence monitoring project in Konya Closed Basin between 2006-2009 by means of GNSS observations. Natural Hazards and Earth System Sciences 10(6):1151-1157

Wakhungu M, et al. (2017) A cost benefit analysis of water recycling in manufacturing industries: A case study of the east african breweries limited, kenya. PhD thesis, University of Nairobi

Xu YS, Ma L, Du YJ, Shen SL (2012) Analysis of urbanisation-induced land subsidence in Shanghai. Natural hazards 63(2):1255-1267

Yang Q, Ke Y, Zhang D, Chen B, Gong H, Lv M, Zhu L, Li X (2018) Multi-scale analysis of the relationship between land subsidence and buildings: A case study in an eastern Beijing Urban Area using the PS-InSAR technique. Remote Sensing 10(7):1006 


\section{Supplementary Files}

This is a list of supplementary files associated with this preprint. Click to download.

- data.pdf 